\title{
BMJ Open COVID-19 infection among international travellers: a prospective analysis
}

To cite: Lunney M, Ronksley PE, Weaver RG, et al. COVID-19 infection among international travellers: a prospective analysis. BMJ Open 2021;11:e050667. doi:10.1136/ bmjopen-2021-050667

- Prepublication history and supplemental material for this paper is available online. To view these files, please visit the journal online (http://dx.doi. org/10.1136/bmjopen-2021050667).

Received 01 March 2021 Accepted 01 June 2021

Check for updates

(C) Author(s) (or their employer(s)) 2021. Re-use permitted under CC BY-NC. No commercial re-use. See rights and permissions. Published by BMJ.

For numbered affiliations see end of article.

Correspondence to Dr Marcello Tonelli; cello@ucalgary.ca

\author{
Meaghan Lunney (D) , ${ }^{1}$ Paul E Ronksley, ${ }^{1}$ Robert G Weaver (D) , ${ }^{2}$ Lianne Barnieh, ${ }^{2}$ \\ Norman Blue, ${ }^{3}$ Marc T Avey, ${ }^{4}$ Elizabeth Rolland-Harris, ${ }^{4}$ Faisal M Khan, ${ }^{5}$ \\ Jack X Q Pang, ${ }^{6}$ Ellen Rafferty, ${ }^{7,8}$ Tayler D Scory, ${ }^{2}$ Lawrence W Svenson (D) , , $7,9,10$ \\ Rachel Rodin, ${ }^{4}$ Marcello Tonelli (D) ${ }^{2}$
}

\section{ABSTRACT}

Objectives This report estimates the risk of COVID-19 importation and secondary transmission associated with a modified quarantine programme in Canada.

Design and participants Prospective analysis of international asymptomatic travellers entering Alberta, Canada.

Interventions All participants were required to receive a PCR COVID-19 test on arrival. If negative, participants could leave quarantine but were required to have a second test 6 or 7 days after arrival. If the arrival test was positive, participants were required to remain in quarantine for 14 days.

Main outcome measures Proportion and rate of participants testing positive for COVID-19; number of cases of secondary transmission.

Results The analysis included 9535 international travellers entering Alberta by air ( $\mathrm{N}=8398)$ or land $(\mathrm{N}=1137)$ that voluntarily enrolled in the Alberta Border Testing Pilot Programme (a subset of all travellers); most (83.1\%) were Canadian citizens. Among the 9310 participants who received at least one test, 200 (21.5 per $1000,95 \% \mathrm{Cl}$ 18.6 to 24.6$)$ tested positive. Sixty-nine per cent $(138 / 200)$ of positive tests were detected on arrival (14.8 per 1000 travellers, $95 \% \mathrm{Cl} 12.5$ to 17.5 ). 62 cases (6.7 per 1000 travellers, $95 \% \mathrm{Cl} 5.1$ to $8.5 ; 31.0 \%$ of positive cases) were identified among participants that had been released from quarantine following a negative test result on arrival. Of 192 participants who developed symptoms, 51 (26.6\%) tested positive after arrival. Among participants with positive tests, four (2.0\%) were hospitalised for COVID-19; none required critical care or died. Contact tracing among participants who tested positive identified 200 contacts; of 88 contacts tested, 22 were cases of secondary transmission (14 from those testing positive on arrival and 8 from those testing positive thereafter). SARS-CoV-2 B.1.1.7 lineage was not detected in any of the 200 positive cases.

Conclusions 21.5 per 1000 international travellers tested positive for COVID-19. Most (69\%) tested positive on arrival and $31 \%$ tested positive during follow-up. These findings suggest the need for ongoing vigilance in travellers testing negative on arrival and highlight the value of follow-up testing and contact tracing to monitor and limit secondary transmission where possible.

\section{INTRODUCTION}

Many countries have imposed border measures aimed at reducing the risk of COVID-19
Strengths and limitations of this study

This study was conducted in a large sample.

- State-of-the art methods were used for COVID-19 testing.

- It is possible that not all contacts were identified or tested, and thus some cases of secondary transmission may have been missed.

- Some participants may have falsely tested negative, although our use of a two-test strategy together with daily symptom monitoring should have reduced this risk.

- Since COVID-19 tests may remain positive for weeks after infection, some participants that tested positive on arrival may have had resolved infection. Repeat testing among participants who tested positive on arrival would have reduced this risk.

importation. ${ }^{12}$ A variety of approaches have been used globally, including symptom questionnaires, temperature checks, testing for COVID-19, and mandatory self-isolation or quarantine. ${ }^{3}$ Since March 2020 Canada has required international travellers who enter the country to quarantine for 14 days in a suitable location, regardless of the presence or absence of symptoms or COVID-19 testing results. While these restrictions are directed at containing the importation of COVID-19, they have likely had substantial social and economic impact.

Prospective analyses evaluating the risk of COVID-19 infection among international travellers are limited, with few data assessing how the risk of testing positive for COVID-19 varies in the days following international travel. ${ }^{4}$ While one study in Saudi Arabia has been published, ${ }^{5}$ participants were required to quarantine at a government facility for 14 days, and the risk of secondary transmission associated with international travel was not evaluated. The decision to require a 14-day quarantine period among travellers was based in part on evidence indicating that COVID-19 infection can develop for up to 14 
days following an exposure. ${ }^{6}$ However, it is uncertain the extent to which different periods of quarantine combined with testing mitigate the risk of community transmission from asymptomatic travellers without known exposure to COVID-19, given the range in timing of exposure and distribution of incubation period(s) among travellers. Several modelling studies have attempted to address this question but have reached conflicting conclusions and may be dependent on the assumptions made to construct the model. ${ }^{7-10}$

This evaluation reports the consequences of a modified quarantine programme. Rather than requiring international travellers to quarantine for 14 days after arrival, the programme released travellers from quarantine after receiving a negative COVID-19 test on arrival, with the requirement that they were tested again at day 6 or 7 and monitored their symptoms daily. Specifically, we assessed the likelihood that international travellers entering Canada tested positive for COVID-19 infection on arrival or at 6-7 days following entry, and determined the proportion of travellers that developed symptoms suggesting COVID-19 infection in the 14 days after arrival. We also estimated the risk of community transmission of COVID-19 associated with the modified quarantine programme and the risk of importing SARS-CoV-2 B.1.1.7 lineage. We hypothesised that the majority of COVID-19 cases would be detected on arrival rather than during follow-up.

\section{METHODS}

\section{Setting}

In March 2020, the Canadian federal government closed borders to everyone except Canadian citizens, permanent residents and their families, and others with a specific reason for travel, such as family reunification. ${ }^{11}$ The border remained open to 'exempt travellers', such as members of flight crews, those transporting goods across the Canada-US border, and those providing certain essential services. ${ }^{12}$ Since the border closure, all international travellers, with the exception of 'exempt travellers', must quarantine for 14 days in an acceptable location following entry to Canada.

The Alberta Border Testing Pilot Programme (ABTPP $)^{13}$ was implemented on 2 November 2020 as a border entry procedure that was aimed at reducing the mandatory 14-day quarantine period for eligible asymptomatic international travellers entering Alberta, Canada. The programme is a partnership between the provincial and federal governments, with a planned enrolment of 52000 participants. The ABTPP is a government programme rather than a study, but the programme includes an embedded evaluation component conducted by an independent academic team and approved by a university-based institutional review board. The current manuscript reports the findings of an interim analysis from the programme evaluation, done after the first 10000 participants completed the programme.

\section{Brief description of the ABTPP}

\section{Participants}

The ABTPP launched on 2 November 2020 and this analysis includes all participants that enrolled between 2 November and 30 November 2020. Travellers were eligible to participate in the ABTPP if they entered Canada via a direct flight to the Calgary International Airport or at the Coutts/Sweetgrass land border crossing; were staying in Alberta for a minimum of 14 days following their arrival in Canada (or arriving and departing directly from Alberta if their duration of stay was <14 days); had an acceptable quarantine plan (including not quarantining in a congregate setting or with a person at high risk of severe COVID-19 disease); were free of any signs and symptoms of COVID- $19^{14}$ at the time of arrival to Canada; and were willing to adhere to the requirements of the ABTPP, including abiding by local and provincial guidance, regulations and legislation. All members of a travel party residing in the same household were required to enrol as a household otherwise all were ineligible to participate. Children under the age of 5 were not required to be tested for COVID-19 but were obligated to participate if an accompanying household member in the same travel party was enrolled.

Travellers that reported contact with a COVID-19 case in the prior 14 days were excluded from the programme. Additionally, if any member of the travelling party had symptoms consistent with COVID-19 infection or had come in contact with a confirmed COVID-19 case, all members of the travel party were excluded. Travellers not eligible or declining to participate were required to quarantine for 14 days, as per federal legislation.

While the ABTPP was open to both exempt and nonexempt travellers, as the former are not required to quarantine whether they participate or not, they are not representative of most international travellers and so were excluded from the current report.

\section{Programme requirements}

All participants aged 5 years or older were required to have a COVID-19 test at the airport or Coutts/Sweetgrass land border crossing immediately on arrival in Canada. Participants were then required to quarantine until a negative arrival test result was received for every member of the travel party. If any member of the travel party tested positive for COVID-19 on arrival or subsequently, all of the travel party were required to re-enter quarantine. If the arrival test was negative, participants were released from quarantine but required to receive a second COVID-19 test 6-7 days following their arrival and to follow preventive measures for 14 days. ${ }^{15}$ Compliance with quarantine measures was verified and enforced by the federal government, as for all entrants to Canada. Potential penalties for non-compliance include transfer to a quarantine facility, fines and/or imprisonment. Participants who chose not to have a second test were required to complete a 14-day quarantine. In approximately $17.7 \%$ of participants, the second test was done on day 5 rather 
than day 6 or 7 , possibly because of miscommunication about nomenclature of the days after arrival. $11.6 \%$ of participants completed their second test on day 8 or later, possibly due to scheduling limitations. Contact tracing of participants who tested positive and their close contacts ${ }^{16}$ (hereafter referred to as 'contacts') was done by public health personnel according to provincial policy. As for the general Alberta population, contacts of participants who tested positive were instructed to quarantine for 14 days and advised to be tested for COVID-19 if possible. ${ }^{16}$

Other requirements associated with participation in the programme included completing a daily electronic report to monitor relevant symptoms associated with COVID-19 for the first 14 days following arrival in Canada. A daily report was required from each member of the household travel party, including children aged $<5$ years. If participants reported symptoms at any point during the 14-day follow-up period, they, and all members of the household, were required to follow public health guidelines.

\section{COVID-19 testing}

Specimens were collected through an oropharyngeal swab and processed through PCR testing. Presence of SARS-CoV-2 viral RNA was detected by next generation sequencing-based assay using the COVIDSeq panel (Illumina Inc) and/or the real-time PCR-based dual target RT-LAMP (reverse-transcriptase loop mediated amplification) assay (IlluDx Inc). A confirmatory RT-LAMP test was performed on all positives and probable positives (detected by COVIDSeq or RT-LAMP assay) after re-extraction of RNA from each individual samples. Retrospective sequencing of 98 SARS-CoV-2 gene targets using COVIDSeq assay was also performed on all positive samples detected by RT-LAMP assay.

\section{Data collection and linkage}

All participants were assigned a unique identification number (UID) at enrolment. Residents of Alberta were asked to provide their personal health number (PHN; provided by the provincial health ministry to access publicly funded healthcare) at registration; if a participant either did not remember or did not have a PHN (in the case of non-Albertans) the UID served as an alternative identifier to link the results of their COVID-19 test to the participant enrolment information.

Participants testing positive for COVID-19 were prioritised for case investigation and contact tracing by Alberta's provincial Communicable Disease Control team. Information collected from case investigations were entered into the provincial Communicable Disease and Outbreak Management (CDOM) database per usual processes. Other information regarding COVID-19 cases, such as healthcare utilisation (hospitalisation, receipt of critical care) or death were collected and updated in CDOM per existing processes. Each participant in CDOM was assigned a unique code, which was used to link any contacts to that participant. ${ }^{16}$ The Lab Information System was searched by name and telephone number to identify contacts of participants who tested positive, and to determine if they were secondary cases linked to participants.

Countries were classified in terms of their COVID-19 risk level (green (low), yellow (intermediate), red (high)) using the European Union's Re-open EU tool ${ }^{17}$ based on the proportion of COVID-19 tests reported as positive (smoothed positivity rate, calculated as a 7-day rolling average) and number of reported cases per 14 days per $100000 .{ }^{18}$ Countries for which data on one or both of these parameters could not be identified were classified as green, yellow or red based on the Centre for Disease Control COVID-19 level. ${ }^{19}$ Data from each 2-week calendar interval was obtained to update the risk classification for each country during the ABTPP. The departure country was collected electronically at enrolment for each participant.

\section{Statistical analysis}

Data were described using numbers and percentages, medians and IQRs, or rates per thousand with 95\% CIs. Results were stratified by mode of arrival (air vs land). To identify potential factors associated with testing positive for COVID-19, we initially used bivariate logistic regression, then fit a multivariable logistic regression model to estimate ORs for a positive test. Penalised maximum likelihood methods were used to account for rare occurrences of the outcome in the bivariate logistic regression models. ${ }^{20} 21$ Factors considered in the multivariable model included participant characteristics (age, sex, nationality, country of residence), days absent from Canada, mode of arrival (air vs land) and the risk of COVID-19 at the departure country on the day of arrival (positivity and cases per 14 days per 100000 residents; we did not include country risk status because it was derived from the other two variables, and $98 \%$ of participants whose departure country could be identified were classified as high risk). We created a full model, then used backwards elimination to arrive at a final, parsimonious model that contained only significant predictors.

In one sensitivity analysis, we explored the possibility that results were affected by clustering by departure country by calculating the intraclass correlation coefficient for positive cases with participants nested within departure country, and by fitting a multi-level logistic regression model where participants were nested within departure country. We also fit a single-level logistic model with SEs adjusted for clustering by departure country. In another sensitivity analysis, we explored the robustness of the final logistic regression model using sex and agestratified analyses (online supplemental material). Stata V.16 was used for all analyses.

\section{Patient and public involvement}

No patients were involved.

\section{RESULTS}

\section{Participant characteristics}

Between 2 November and 30 November 2020, 10075 travellers enrolled in the ABTPP (online supplemental 
Table 1 Characteristics of cohort participants

\begin{tabular}{|c|c|c|c|}
\hline & Arrived by air & Arrived by land & Total \\
\hline & $\mathbf{N}(\%)$ & $\mathbf{N}(\%)$ & $\mathbf{N}(\%)$ \\
\hline N & $8398(88.1)$ & $1137(11.9)$ & 9535 \\
\hline \multicolumn{4}{|l|}{ Age (years) at time of enrolment } \\
\hline Median (IQR) & $47(30-58)$ & $41(23-57)$ & $46(30-58)$ \\
\hline$<5$ & $168(2.0)$ & $57(5.0)$ & $225(2.4)$ \\
\hline $5-17$ & $403(4.8)$ & $99(8.7)$ & $502(5.3)$ \\
\hline $18-34$ & $2147(25.6)$ & $310(27.3)$ & $2456(25.8)$ \\
\hline $35-49$ & $1878(22.4)$ & $234(20.6)$ & $2112(22.2)$ \\
\hline $50-64$ & 2898 (34.5) & $313(27.5)$ & $3211(33.7)$ \\
\hline$\geq 65$ & $904(10.8)$ & $124(10.9)$ & $1028(10.8)$ \\
\hline \multicolumn{4}{|l|}{ Sex } \\
\hline Male & $4380(52.2)$ & $643(56.6)$ & $5023(52.7)$ \\
\hline Female & $4005(47.7)$ & $490(43.1)$ & $4495(47.1)$ \\
\hline Other & $13(0.2)$ & $4(0.4)$ & $17(0.2)$ \\
\hline \multicolumn{4}{|l|}{ Citizenship status } \\
\hline Canadian citizen & 7049 (83.9) & $878(77.2)$ & 7927 (83.1) \\
\hline Permanent resident & $703(8.4)$ & $116(10.2)$ & $819(8.6)$ \\
\hline Foreign citizen & $646(7.7)$ & $143(12.6)$ & $789(8.3)$ \\
\hline \multicolumn{4}{|c|}{ Number of household members in travel party (including traveller) } \\
\hline 1 & $4461(53.1)$ & $469(41.2)$ & $4930(51.7)$ \\
\hline 2 & $2941(35.0)$ & $379(33.3)$ & $3320(34.8)$ \\
\hline 3 & $470(5.6)$ & $116(10.2)$ & $586(6.2)$ \\
\hline 4 or more & $526(6.3)$ & $173(15.2)$ & $699(7.3)$ \\
\hline \multicolumn{4}{|l|}{ Reason for travel } \\
\hline Personal & $7486(89.1)$ & $884(77.8)$ & $8370(87.8)$ \\
\hline Work & $605(7.2)$ & $94(8.3)$ & $699(7.3)$ \\
\hline Study & $172(2.0)$ & $41(3.6)$ & $213(2.2)$ \\
\hline Not provided & $135(1.6)$ & $118(10.4)$ & $253(2.6)$ \\
\hline Days absent from Canada, median (IQR) ${ }^{\star}$ & $15(8-34)$ & $16(7-85)$ & $15(8-36)$ \\
\hline \multicolumn{4}{|l|}{ Departure country } \\
\hline USA & $5160(61.4)$ & $1125(98.9)$ & $6228(65.9)$ \\
\hline Mexico & $1547(18.4)$ & $12(1.1)$ & $1559(16.4)$ \\
\hline Netherlands & $471(5.6)$ & 0 & $471(4.9)$ \\
\hline Other & $688(8.2)$ & 0 & $688(7.2)$ \\
\hline Unknown & $532(6.3)$ & 0 & $532(5.6)$ \\
\hline \multicolumn{4}{|l|}{ Risk of COVID-19 at departure country $†$} \\
\hline Red & $7692(91.6)$ & $1137(100)$ & $8829(92.6)$ \\
\hline Yellow & $117(1.4)$ & 0 & $117(1.2)$ \\
\hline Green & $57(0.7)$ & 0 & $57(0.6)$ \\
\hline Unknown & $532(6.3)$ & 0 & $532(5.6)$ \\
\hline \multicolumn{4}{|c|}{ COVID-19 smoothed positivity at departure country } \\
\hline$\leq 0.2$ & $6140(73.1)$ & 1125 (98.9) & 7265 (76.2) \\
\hline$>0.2$ & 1695 (20.2) & $12(1.1)$ & 1707 (17.9) \\
\hline Unknown & $563(6.7)$ & 0 & $563(5.9)$ \\
\hline
\end{tabular}


Table 1 Continued

\begin{tabular}{|c|c|c|c|}
\hline & Arrived by air & Arrived by land & Total \\
\hline & N (\%) & N (\%) & $\mathbf{N}(\%)$ \\
\hline$\leq 200$ & $1812(21.6)$ & $12(1.1)$ & $1824(19.1)$ \\
\hline Unknown & $563(6.7)$ & 0 & $563(5.9)$ \\
\hline
\end{tabular}

$\mathrm{N}(\%)$ unless otherwise indicated.

*Not applicable for 789 participants who were foreign citizens.

†Positivity and notification rates from https://ourworldindata.org, and classification of the departure country risk was calculated from these rates, using the European Union tool (https://reopen.europa.eu/en); see the Methods section.

figure 1). Of these travellers, 9535 were non-exempt travellers and were included in the current report. These 9535 participants arriving between 2 November and 30 November, included 8398 entering by air (56.4\% of international passengers arriving at the Calgary airport) and 1137 entering by road $(32.2 \%$ of non-commercial travellers entering Canada at the Coutts/Sweetgrass border crossing). Among these 9535 participants, median age was 46 years (IQR 30-58) and 225 were less than 5 years of age; the latter were exempted from testing for COVID-19.

The 9535 participants entered Canada in 6977 distinct travel parties that had a mean number of 1.4 participants (median 1.0; range 1-8); of these, 8398 (88.1\%) entered by air. The large majority of participants were Canadian citizens $(83.1 \%)$; other characteristics of ABTPP participants are shown in table 1. Data on risk of COVID-19 in the departure country were not available for 532 (5.6\%) participants due to a technical error in data collection. Of the remaining $9003,98.1 \%, 1.3 \%$ and $0.6 \%$ of participants arrived from a departure country with red, yellow or green COVID-19 risk, respectively.

\section{Participants with positive COVID-19 tests}

Among the 9310 participants aged $\geq 5$ years that were tested for COVID-19, 200 (21.5 per 1000; 95\% CI 18.6 to 24.6) tested positive at arrival or within 14 days following entry to Canada; the proportion was similar for those arriving by air or by land (table 2). Sixty-nine per cent $(138 / 200)$ of these positive tests were detected on arrival (14.8 per 1000 travellers, $95 \%$ CI 12.5 to $17.5 ; 69.0 \%$ of positive cases) and thus occurred among participants who remained under a quarantine order. Among participants with positive tests, four $(2.0 \%)$ were hospitalised for COVID-19; none required critical care or died.

Sixty-two cases (6.7 per 1000 travellers, 95\% CI 5.1 to 8.5; $31.0 \%$ of all positive cases) were identified during follow-up among participants that had been released from quarantine following a negative test result on arrival. Of these cases, 51 (5.5 per 1000 travellers, $95 \%$ CI 4.1 to 7.2; $25.5 \%$ of all positive tests) were detected through a follow-up test occurring on day 7 or prior and the remaining 11 cases (1.2 per 1000 travellers, 95\% CI 0.6

Table 2 COVID-19 infection and its consequences by mode of travel

\begin{tabular}{|c|c|c|c|}
\hline & Arrived by air & Arrived by land & Total \\
\hline $\mathrm{N}$ & 8230 & 1080 & 9310 \\
\hline Positive cases & $\begin{array}{l}180(2.2 \%) \\
(95 \% \mathrm{Cl} 1.9 \text { to } 2.5)\end{array}$ & $\begin{array}{l}20(1.9 \%) \\
(95 \% \mathrm{Cl} 1.1 \text { to } 2.8)\end{array}$ & $\begin{array}{l}200(2.1 \%) \\
(95 \% \mathrm{Cl} 1.9 \text { to } 2.5)\end{array}$ \\
\hline $\begin{array}{l}\text { Incidence of positive COVID-19 tests among } \\
\text { ABTPP participants, per } 100000 \text { participants }\end{array}$ & $\begin{array}{l}2187 \\
\text { (95\% Cl } 1882 \text { to } 2527)\end{array}$ & $\begin{array}{l}1852 \\
(95 \% \mathrm{Cl} 1135 \text { to } 2485)\end{array}$ & $\begin{array}{l}2148 \\
(95 \% \text { Cl } 1863 \text { to } 2464)\end{array}$ \\
\hline Positive tests on day 5 & 11 & 1 & 12 \\
\hline Positive tests at day $6-7$ & 35 & 4 & 39 \\
\hline Positive tests at day $8-12$ & 10 & 1 & 11 \\
\hline Symptoms at any time & 178 & 14 & 192 \\
\hline
\end{tabular}

Test incidence among ABTPP participants includes two tests for most participants.

Participants who tested positive within 14 days of arrival (ie, at either arrival or during follow-up).

ABTPP, Alberta Border Testing Pilot Programme. 


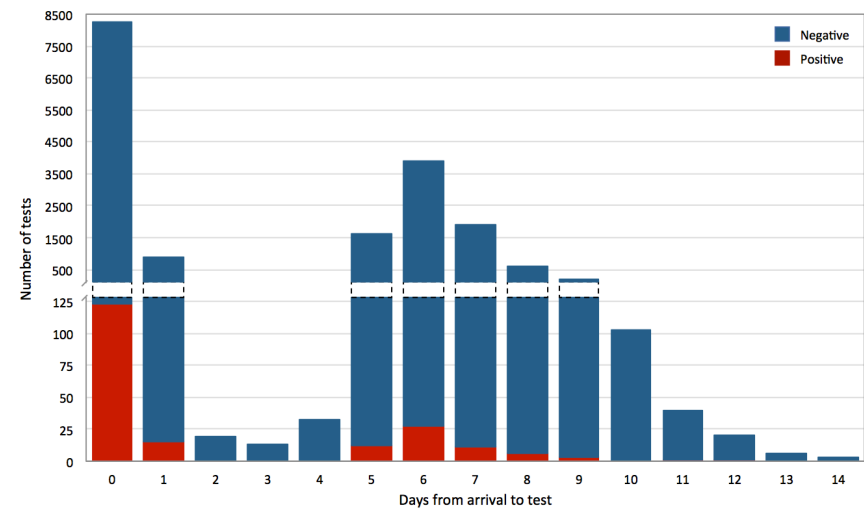

Figure 1 Proportion of positive COVID-19 tests among all participants. The proportion of tests done on each day that were positive for COVID-19 infection. Tests were scheduled for arrival (day 0) and in follow-up (days 6-7). Some patients had the follow-up test done on day 5 rather than 6-7.

Additional participants had extra tests done outside the two scheduled tests because of symptoms.

to $2.1 ; 5.5 \%$ of all positive tests; ) were detected on a test occurring on day 8 or later ( 6 on day 8,3 on day 9,1 on day 11,1 on day 12) (figure 1 ).

Table 3 shows the full multivariable logistic regression model for testing positive, and the final parsimonious model. In the final model, participants aged 35-49 years were more likely than other age groups to test positive for COVID-19 (OR 2.08, 95\% CI 1.20 to 3.62; referent age $\geq 65$ ). Canadian residents were also more likely to test positive (OR 2.21, 95\% CI 1.39 to 3.51) compared with residents of other countries. Participants arriving from countries with positivity rates (ie, the proportion of tests that were positive in the departure country) $>0.2$ were more likely to test positive compared with those with positivity rates $\leq 0.2$ (OR $3.30,95 \%$ CI 1.68 to 6.46 ), as were participants arriving from countries with 14-day notification rates $>200$ per 100000 compared with those with notification rates $\leq 200$ per 100000 (OR 2.62, 95\% CI 1.30 to 5.31). Other characteristics such as shorter absence from Canada were significantly associated with testing positive in bivariate analysis. However, only age, country of residence and departure country positivity and notification rates remained statistically significant in the full multivariable model, and were retained in the final model.

Participants arriving from countries with green, yellow or red risk status contributed 0,1 and 183 cases of COVID19 , respectively, although the proportion of infected travellers did not significantly differ by level of COVID-19 risk $(\mathrm{p}=0.23)$. The departure country was unknown in 16 cases of COVID-19.

SARS-CoV-2 B.1.1.7 lineage was not detected in any of the 200 positive cases.

In the first sensitivity analysis, we found that in an intercept-only multi-level logistic regression model for a positive test, with participants nested within departure country, the intraclass correlation coefficient was 0.0015 , indicating very weak correlation on the outcome within departure country. Furthermore, when we fit a multilevel model with the same predictors as the final singlelevel logistic model, we found that the coefficients were essentially identical to the original model, and the likelihood ratio test comparing the non-nested and multi-level models was non-significant $\left(\chi^{2}=\sim 0, p=\sim 1\right)$. In addition, we re-fit the final single-level logistic model with SEs adjusted for clustering by departure country. Online supplemental table 1 compares the two versions of the final model, with SEs adjusted and not adjusted for clustering. Some CIs are wider, and some narrower, but there were no changes to statistical significance with adjustment for clustering.

In the second sensitivity analysis, we explored the effect on the final model of stratifying by sex and age group (online supplemental tables 2 and 3). While the point estimates for the ORs for covariates differ between the models for the subgroups, the CIs overlap substantially in all cases, and there is no evidence that the model differs significantly between subgroups.

\section{Secondary transmission from participants}

Among all 200 participants with a positive test, 194 (97\%) could be linked to the provincial CDOM dataset. These 194 participants had a total of 200 identified contacts who were instructed to self-isolate for 14 days (median number of contacts per case 0 , range $0-5$ ). Of the 200 contacts, 88 had a COVID-19 test and of these 22 (25.0\% of those tested; $11.0 \%$ of all contacts) tested positive for COVID-19 at some point during their 14-day self-isolation. The proportion of cases that had contact with at least one other person was similar for those who tested positive on arrival $(51 / 134(38.1 \%))$ (ie, that had been in quarantine) versus during follow-up (24/60 (40.0\%), $\mathrm{p}=0.79)$. Likewise, the proportion of cases that resulted in at least one secondary case was similar for those who tested positive on arrival compared with follow-up (arrival: 9/134 $(6.7 \%)$ vs during follow-up: $7 / 60(11.7 \%), p=0.27)$, as was the number of secondary cases transmitted (arrival: 14 cases, vs during follow-up: 8 cases).

\section{Proportion of participants with symptoms consistent with COVID-19 infection}

One hundred and ninety-two participants $(2.1 \%)$ aged $\geq 5$ years reported one or more symptoms on at least 1 day within 14 days of their arrival (table 2). Of these, $26.6 \%$ $(51 / 192)$ tested positive either at arrival $(20.3 \%, 39 / 192)$ or during follow-up $(6.3 \%, 12 / 192)$. Of the 39 who tested positive on arrival, 36 had symptom onset between 1 and 4 days after the test, while of the 12 who tested positive in follow-up, 7 had symptom onset 1-4 days after the test, with only 3 reporting symptoms before the test.

Of the 192 participants with symptoms, 69.8\% $(134 / 192)$ reported symptom onset during the first 6 days after arrival. Of these, $29.1 \%(39 / 134)$ tested positive at their arrival test and an additional 3 participants tested positive at a later date. Fifty-eight participants reported symptom onset on day 7 or later; of these $15.5 \%(9 / 58)$ 
Table 3 Association between participant characteristics and testing positive for COVID-19 infection

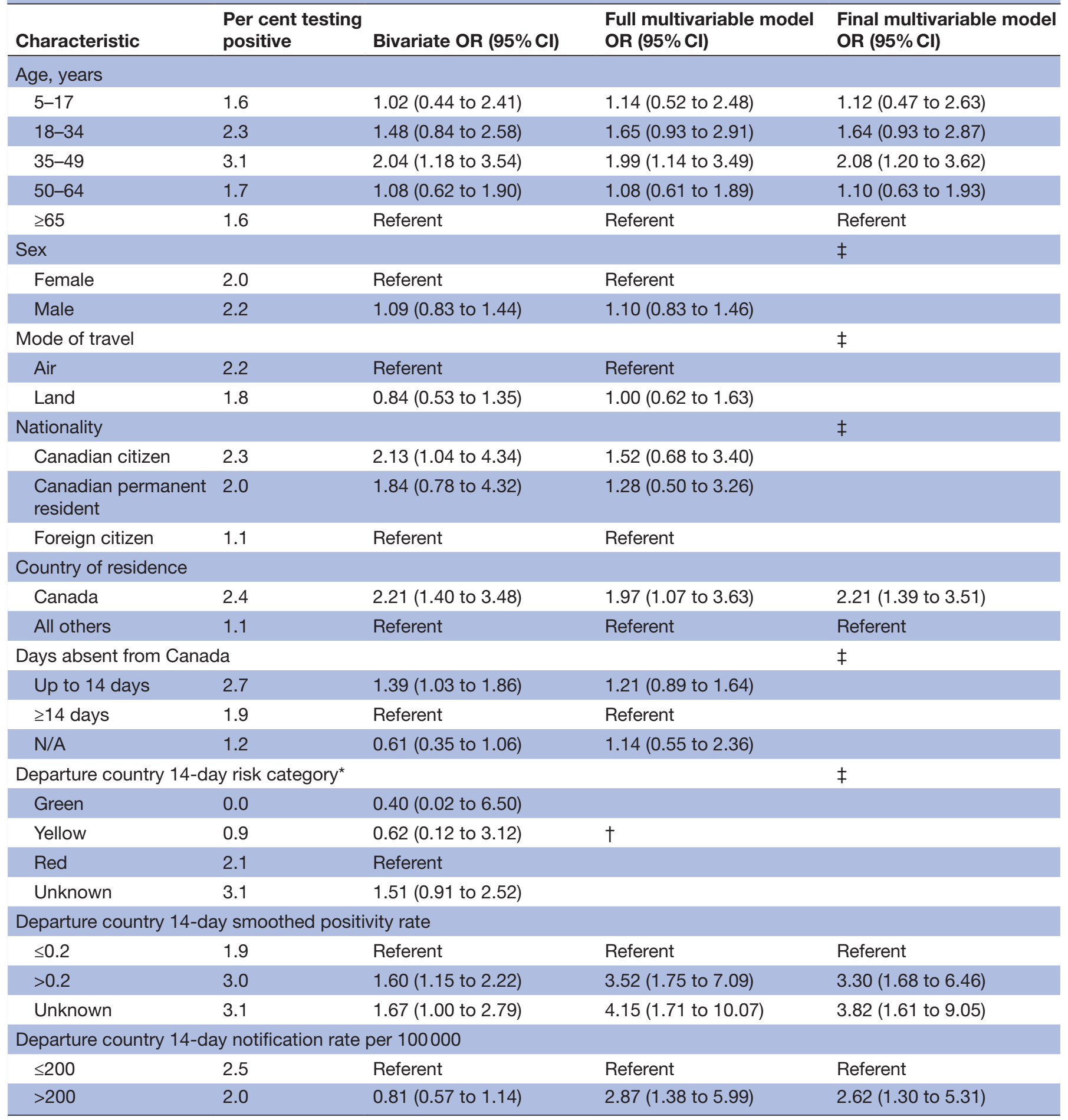

Smoothed positivity refers to the proportion of within-country COVID-19 tests reported as positive, averaged over 7 days for the departure country. Notification rate refers to the 14-day rate of within-country COVID-19 infection per 100000 population. Positivity and notification rate were based on data from ourworldindata.org for the departure country, assessed at the arrival date. The 14-day risk category was based on the positivity and notification rate, using the heat map at reopen.europa.eu/en.

The Hosmer Lemeshow goodness-of-fit test for the final multivariable model: $p=0.54$.

*There were no positive cases among the 57 participants who had arrived from green (low risk) countries, so a bivariate OR could not be calculated using maximum likelihood procedures. Instead, ORs were estimated using penalised maximum likelihood methods.

†The risk category was not included in the full model as it was derived from positivity and case rate, and because $98 \%$ of participants whose departure country was known were classified as high risk.

$\ddagger$ These variables were dropped from the final multivariable model as they were non-significant in the full model. 


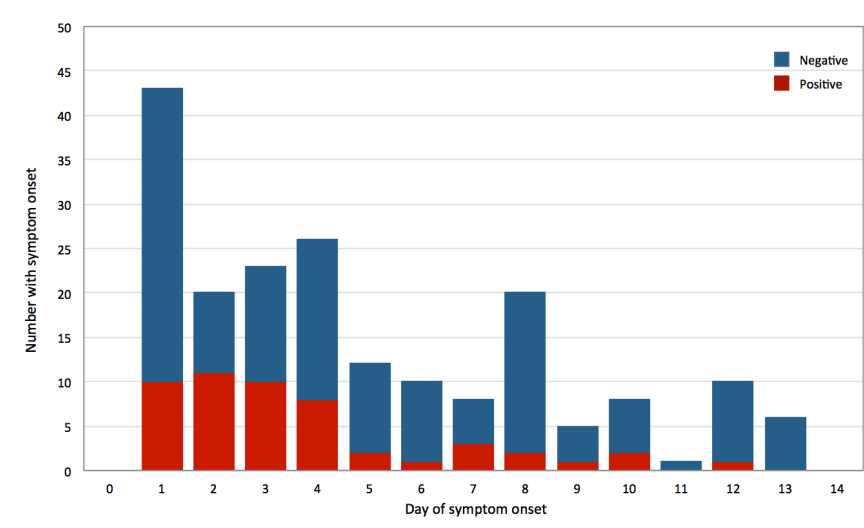

Figure 2 Proportion of positive COVID-19 tests among participants who reported symptoms. The day of symptom onset among symptomatic Alberta Border Testing Pilot Programme participants as well as the proportion of such participants who tested positive at any time during the 14 days after arrival.

tested positive. The relation between symptoms and positive COVID-19 tests is shown in figure 2.

When travellers arriving by air were compared with those arriving by land, no differences were detected in the proportion of positive travellers reporting symptoms or the timing of symptoms among those who became symptomatic (table 2).

\section{Likelihood of testing positive for COVID-19 among ABTPP participants as compared with other groups}

The cumulative incidences of COVID-19 infection in the Albertan and Canadian general populations during the analysis period were 684 and 402 per 100000 population, respectively, compared with a contemporaneous incidence of 2148 per 100000 among ABTPP participants.

The 200 cases of COVID-19 reported among the ABTPP participants that enrolled during 2 November to 30 November, represent $0.5 \%$ of the 42488 cases reported in the general Alberta population during the same period. ${ }^{22}$

\section{DISCUSSION}

Mitigating the risk of COVID-19 importation by quarantine and testing is a key issue globally, but few prospective analyses explore the effectiveness of these measures. We evaluated the likelihood that international travellers who denied symptoms of COVID-19 infection and were subject to a modified quarantine programme ${ }^{13}$ would test positive for COVID-19 on arrival and at 6-7 days following arrival. We also estimated the rate of secondary transmission from programme participants to close contacts to inform policy on 14-day quarantine requirements. The overall proportion of participants who tested positive was 21.5 per 1000 (95\% CI 18.6 to 24.6) and was similar for travellers arriving by air compared with those arriving by land. Most $(69.0 \%)$ participants who tested positive for COVID-19 infection did so at the arrival test, whereas $25.5 \%$ of cases tested positive at the follow-up test on or before days $6-7$ after arrival and $5.5 \%$ tested positive at a later date. These findings suggest the need for ongoing vigilance in travellers testing negative on arrival and highlight the potential value of follow-up testing.

On average, one contact was identified for each infected participant; these contacts led to a total of 22 cases of secondary transmission. Quarantine did not appear to fully protect against transmission to contacts. Travellers who received a negative first result and were allowed to leave quarantine did not cause a greater number of secondary infections $(n=8)$ than those who remained in quarantine for 14 days $(\mathrm{n}=14)$. ABTPP participants were required to follow individual and community public health measures, including restrictions on entering high-risk settings; mask mandates; and regulations on maximum gathering sizes and business closures, all of which may have mitigated community spread after release from quarantine. ${ }^{23} 24$ Tertiary transmission is also possible, although all contacts were asked to self-isolate for 14 days.

Symptom reporting appeared to be a weak method for identifying cases. ${ }^{25}$ Approximately three-quarters (74.5\%) of travellers who tested positive did not report symptoms at any time during follow-up, and the proportion with severe illness leading to hospitalisation was low (2.0\% of COVID-19 positive travellers) with none requiring critical care. Similar to the general population undergoing testing, among participants who reported symptoms consistent with COVID-19 infection, most (73.4\%) did not have laboratory evidence of infection. These results suggest that the addition of a two-test strategy strengthens early identification and isolation of cases and contacts. Although testing of international travellers might also help to reduce the risk of more infectious strains of COVID-19, we did not detect the SARS-CoV-2 B.1.1.7 lineage in any of the 200 positive cases during this time period.

During the analysis period, factors associated with a higher risk of COVID-19 infection included age and Canadian citizenship. We speculate that within the population studied, the latter is a proxy for certain types of leisure travel that might increase the risk of exposure while abroad. It also appeared that higher departure country COVID-19 positivity and notification rates were both associated with greater risk of infection.

An as-yet unpublished study tested 16361 international travellers on arrival and then on days 7 and 14. These participants were required to quarantine for 14-days after arrival (regardless of test result) and loss-to-follow-up was approximately $28 \%$ by the third (day 14 ) test. ${ }^{4}$ Similar to our results, these authors also found that approximately $67 \%$ of all positive tests occurred on arrival, with $6 \%$ occurring on day 14 . A second study of 337 French nationals who were tested on repatriation from Wuhan and on day 5 thereafter found that no participants tested positive. ${ }^{26}$ Finally, a recent modelling study suggested that testing on arrival would detect $77.2 \%$ of all positive cases. ${ }^{27}$ Other modelling studies have reached varying conclusions, although most have found that results are 
sensitive to the extent of compliance with quarantine..$^{7-10}$ Our data extend the available literature by evaluating the real-world risk of COVID-19 importation and secondary transmission when a mandatory 14-day quarantine for asymptomatic international travellers is replaced by a twotest strategy and daily symptom reporting.

Most $(65.9 \%)$ ABTPP participants arrived from the USA, where contemporaneous rates of infection were double those in Alberta. Although the overall rate of infection among ABTPP travellers was substantially higher than contemporaneous rates in the general Alberta population, the absolute contribution of international travel to the provincial incidence of COVID-19 was relatively small. Further, all ABTPP participants were tested, whereas only a subsample of the Albertan population is tested, and so comparing the infection rate between these two groups requires caution. Decision-makers should carefully consider the incidence of COVID-19 infection, the effectiveness of existing preventive measures and health system capacity in their jurisdiction ${ }^{28}$ when assessing the optimal approach to border measures. For example, allowing one or two infected travellers per day to enter a region would have substantially different implications for countries with a low incidence rate, for example, New Zealand (incidence of COVID-19 in mid-November 2020: 0.01 per 1000 per 14 days) than it would for a country with a much higher incidence rate, for example, the UK (4.8 per 1000). In addition, the number of international travellers entering Canada in November 2020 was $>90 \%$ lower than in 2019. Decision-makers should also consider the potential for future increases in travel volumes when assessing the feasibility of post-arrival testing programmes.

Our analysis has certain limitations that should be considered when interpreting results. First, while an experienced team of public health professionals based in Alberta's provincial healthcare system attempted to identify all contacts for ABTPP participants who tested positive, it is possible that not all contacts were identified or tested, and thus some cases of secondary transmission may have been missed. Second, the source of infection could not be determined among travellers, and so those testing negative at arrival and positive at follow-up may have become infected in the community after being released from quarantine. Similarly, we were unable to identify whether contacts of travellers were household members or travellers themselves, which has limitations to how the secondary transmission risk is perceived. Third, some participants may have falsely tested negative, although our use of a two-test strategy together with daily symptom monitoring should have reduced this risk. Fourth, since COVID-19 tests may remain positive for weeks after infection, some participants that tested positive on arrival may have had resolved infection. Repeat testing among participants who tested positive on arrival would have reduced this risk. Fifth, we were unable to identify the departure country in all cases, likely leading to some misclassification of country COVID-19 risk. Sixth, participants aged $<5$ years were not tested for
COVID-19, and thus some cases may have been missed in this population. Seventh, because the ABTPP was a voluntary programme and not all international travellers were tested, there is a risk of selection bias as the prevalence of COVID-19 could be systematically different in the ABTPP from the broader population of all international travellers. Finally, these data were collected in one Canadian province over 1 month, while the epidemiology of the pandemic is continuously evolving. In particular, observations regarding test positivity, participant characteristics and secondary transmission could change as more participants are enrolled. Substantial changes in the prevalence of COVID-19 at the origin or destination of travellers might influence the prevalence of infection, although likely not the proportion of cases detected on arrival as opposed to at 6-7 days after entry.

In conclusion, we found that $2.1 \%$ of asymptomatic international travellers entering Alberta, Canada tested positive for COVID-19, with nearly three-quarters of positive travellers reporting no symptoms of infection at any time during follow-up. The majority of travellers who tested positive did so on arrival, with less than onethird testing positive at $6-7$ days and few testing positive thereafter. These findings suggest the need for ongoing vigilance in international travellers who test negative on arrival and highlight the value of follow-up testing.

\section{Author affiliations}

${ }^{1}$ Department of Community Health Sciences, Cumming School of Medicine, University of Calgary, Calgary, Alberta, Canada

${ }^{2}$ Department of Medicine, Cumming School of Medicine, University of Calgary, Calgary, Alberta, Canada

${ }^{3}$ Office of the Chief Medical Officer of Health, Alberta Health, Government of Alberta, Edmonton, Alberta, Canada

${ }^{4}$ Public Health Agency of Canada, Ottawa, Ontario, Canada

${ }^{5}$ Cumming School of Medicine, University of Calgary, Calgary, Alberta, Canada

${ }^{6}$ Provincial Population and Public Health, Alberta Health Services, Calgary, Alberta, Canada

${ }^{7}$ Analytics \& Performance Reporting Branch, Alberta Health, Government of Alberta, Edmonton, Alberta, Canada

${ }^{8}$ Institute of Health Economics, Edmonton, Alberta, Canada

${ }^{9}$ Division of Preventive Medicine, Faculty of Medicine and Dentistry, University of Alberta, Edmonton, Alberta, Canada

${ }^{10}$ School of Public Health, University of Alberta, Edmonton, Alberta, Canada

\section{Twitter Lawrence W Svenson @Larry_Svenson}

Contributors ML, PER, RGW, LB, NB, MTA, FMK, JXQP, LWS, RR, and MT made substantial contributions to conception and design. JXQP, FMK, and ER contributed to data collection. RGW carried out data analysis. ML, PER, RGW, LB, MTA, ERH, FMK, ER, TDS, LWS, RR, and MT interpreted the data. ML and MT wrote the first draft of the manuscript and all authors were involved in revising it critically for important intellectual content. All authors provide final approval of the version to be published and agreed to be accountable for all aspects of the work.

Funding This work was funded by a contract from the Government of Alberta which received a grant from the Public Health Agency of Canada. Additional funding (to MT) was provided by a Foundation grant from the Canadian Institutes of Health Research (award number: FDN-143211). MT was supported by the David Freeze Chair in Health Services Research at the University of Calgary.

Competing interests None declared.

Patient consent for publication Not required.

Ethics approval The analysis was reviewed and approved by the University of Calgary Conjoint Health Research Ethics Board (CHREB) (REB20-2147). Though all 
participants provided consent to participate in the pilot programme, CHREB waived the requirement for informed consent among research participants.

Provenance and peer review Not commissioned; externally peer reviewed.

Data availability statement № data are available.

Supplemental material This content has been supplied by the author(s). It has not been vetted by BMJ Publishing Group Limited (BMJ) and may not have been peer-reviewed. Any opinions or recommendations discussed are solely those of the author(s) and are not endorsed by BMJ. BMJ disclaims all liability and responsibility arising from any reliance placed on the content. Where the content includes any translated material, BMJ does not warrant the accuracy and reliability of the translations (including but not limited to local regulations, clinical guidelines, terminology, drug names and drug dosages), and is not responsible for any error and/or omissions arising from translation and adaptation or otherwise.

Open access This is an open access article distributed in accordance with the Creative Commons Attribution Non Commercial (CC BY-NC 4.0) license, which permits others to distribute, remix, adapt, build upon this work non-commercially, and license their derivative works on different terms, provided the original work is properly cited, appropriate credit is given, any changes made indicated, and the use is non-commercial. See: http://creativecommons.org/licenses/by-nc/4.0/.

ORCID iDs

Meaghan Lunney http://orcid.org/0000-0003-4954-0529

Robert G Weaver http://orcid.org/0000-0002-8403-857X

Lawrence W Svenson http://orcid.org/0000-0002-3391-578X

Marcello Tonelli http://orcid.org/0000-0002-0846-3187

\section{REFERENCES}

1 Linka K, Peirlinck M, Sahli Costabal F, et al. Outbreak dynamics of COVID-19 in Europe and the effect of travel restrictions. Comput Methods Biomech Biomed Engin 2020;23:710-7.

2 Wells CR, Sah P, Moghadas SM, et al. Impact of international travel and border control measures on the global spread of the novel 2019 coronavirus outbreak. Proc Natl Acad Sci U S A 2020;117:7504-9.

3 Hale T, Boby T, Angrist N. Variation in government responses to COVID19 version 9.0. Blavatnik school of government working paper, 2020. Available: www.bsg.ox.ac.uk/covidtracker

4 Goel V, Bulir D, De Propetis E. COVID-19 International Border Surveillance Cohort Study at Toronto's Pearson Airport. medRxiv:2021.02.25.21252404.

5 Al-Tawfiq JA, Sattar A, Al-Khadra H, et al. Incidence of COVID-19 among returning travelers in quarantine facilities: a longitudinal study and lessons learned. Travel Med Infect Dis 2020;38:101901.

6 Lauer SA, Grantz KH, Bi Q, et al. The incubation period of coronavirus disease 2019 (COVID-19) from publicly reported confirmed cases: estimation and application. Ann Intern Med 2020;172:577-82.

7 Arino J, Bajeux N, Portet S, et al. Quarantine and the risk of COVID-19 importation. Epidemiol Infect 2020;148:e298.

8 van de Toorn W, D-Y O, Bourquain D. COVIDStrategyCalculator: a standalone software to assess testing- and quarantine strategies for incoming travelers, contact person management and de-isolation. medRxiv:2020.11.18.20233825.

9 Russell WA, Buckeridge DL. Effectiveness of quarantine and testing to prevent COVID-19 transmission from arriving travelers. medRxiv:2020.11.02.20224568.
10 Clifford S, Quilty BJ, Russell TW. Strategies to reduce the risk of SARS-CoV-2 re-introduction from international travellers. medRxiv:2020.07.24.20161281.

11 Government of Canada. Orders in Council [Internet], 2020. Available: https://orders-in-council.canada.ca/attachment.php?attach $=38959 \&$ lang=en [Accessed 05 May 2021]

12 Government of Canada. List of Acts and Regulations [Internet], 2020. Available: https://www.canada.ca/en/public-health/corporate/ mandate/about-agency/acts-regulations/list-acts-regulations.html [Accessed 05 May 2021].

13 Government of Alberta. International Border Testing Pilot Program [Internet], 2020. Available: https://www.alberta.ca/internationalborder-pilot-project.aspx [Accessed 03 Jan 2021].

14 Alberta Health Services. Information for Albertans - COVID-19 [Internet], 2020. Available: https://www.albertahealthservices.ca/ topics/Page16997.aspx - sign [Accessed 08 Jan 2021].

15 Government of Canada. Alberta COVID-19 Border Testing Pilot Program [Internet], 2021. Available: https://www.canada.ca/en/ public-health/services/diseases/2019-novel-coronavirus-infection/ latest-travel-health-advice/alberta-covid-19-border-testing-pilotprogram.html [Accessed 05 May 2021].

16 Alberta Health Services. COVID-19 Close Contacts Identification Guide [Internet], 2020. Available: https://www.albertahealthservices. ca/assets/info/ppih/if-ppih-covid-19-contact-tracing-guide.pdf [Accessed 05 May 2021].

17 European Union. Re-open EU [Internet], 2020. Available: https:// reopen.europa.eu/en [Accessed 08 Jan 2021].

18 Our World In Data. The share of COVID-19 tests that are positive. [Internet], 2021. Available: https://ourworldindata.org/grapher/ positive-rate-daily-smoothed [Accessed 06 Jan 2021].

19 Centers for Disease Control and Prevention. Travel Health Notices [Internet], 2021. Available: https://wwwnc.cdc.gov/travel/notices [Accessed 08 Jan 2021].

20 Firth D. Bias reduction of maximum likelihood estimates. Biometrika 1993;80:27-38

21 Heinze G, Schemper M. A solution to the problem of separation in logistic regression. Stat Med 2002;21:2409-19.

22 Government of Alberta. COVID-19 Alberta statistics [Internet], 2021. Available: https://www.alberta.ca/stats/covid-19-alberta-statistics. htm\#total-cases [Accessed 17 Jan 2021].

23 Mitze T, Kosfeld R, Rode J, et al. Face masks considerably reduce COVID-19 cases in Germany. Proc Natl Acad Sci U S A 2020;117:32293-301.

24 Chu DK, Akl EA, Duda S, et al. Physical distancing, face masks, and eye protection to prevent person-to-person transmission of SARS-CoV-2 and COVID-19: a systematic review and meta-analysis. Lancet 2020;395:1973-87.

25 Dollard P, Griffin I, Berro A, et al. Risk assessment and management of COVID-19 among travelers arriving at designated U.S. Airports, January 17-September 13, 2020. MMWR Morb Mortal Wkly Rep 2020;69:1681-5.

26 Lagier JC, Colson P, Tissot Dupont $\mathrm{H}$, et al. Testing the repatriated for SARS-Cov2: should laboratory-based quarantine replace traditional quarantine? Travel Med Infect Dis 2020;34:101624.

27 Dickens BL, Koo JR, Lim JT, et al. Strategies at points of entry to reduce importation risk of COVID-19 cases and reopen travel. $J$ Travel Med 2020;27:taaa141.

28 Russell TW, Wu JT, Clifford S, et al. Effect of internationally imported cases on internal spread of COVID-19: a mathematical modelling study. Lancet Public Health 2021;6:e12-20. 